OAK RIDGE

NATIONAL LABORATORY

MANAGED BY UT-BATTELLE

FOR THE DEPARTMENT OF ENERGY

ORNL/TM-2000/263

\title{
Cavitation in a Mercury Target
}

\author{
C. D. West
}

$\frac{\text { UT-BATTELLEE }}{\text { ORNL-27 (4-00) }}$ 


\section{DOCUMENT AVAILABILITY}

Reports produced after January 1, 1996, are generally available free via the U.S. Department of Energy (DOE) Information Bridge.

Web site $\mathrm{http}: / / w w w . o s t i . g o v / b r i d g e$

Reports produced before January 1, 1996, may be purchased by members of the public from the following source.

National Technical Information Service

5285 Port Royal Road

Springfield, VA 22161

Telephone 703-605-6000 (1-800-553-6847)

TDD 703-487-4639

Fax 703-605-6900

E-mail info@ntis.fedworld.gov

Web site http://www.ntis.gov/support/ordernowabout.htm

Reports are available to DOE employees, DOE contractors, Energy Technology Data Exchange (ETDE) representatives, and International Nuclear Information System (INIS) representatives from the following source.

Office of Scientific and Technical Information

P.O. Box 62

Oak Ridge, TN 37831

Telephone 865-576-8401

Fax 865-576-5728

E-mail reports@adonis.osti.gov

Web site http://www.osti.gov/contact.html

This report was prepared as an account of work sponsored by an agency of the United States Government. Neither the United States Government nor any agency thereof, nor any of their employees, makes any warranty, express or implied, or assumes any legal liability or responsibility for the accuracy, completeness, or usefulness of any information, apparatus, product, or process disclosed, or represents that its use would not infringe privately owned rights. Reference herein to any specific commercial product, process, or service by trade name, trademark, manufacturer, or otherwise, does not necessarily constitute or imply its endorsement, recommendation, or favoring by the United States Government or any agency thereof. The views and opinions of authors expressed herein do not necessarily state or reflect those of the United States Government or any agency thereof. 
ORNL/TM-2000/263

\title{
CAVITATION IN A MERCURY TARGET
}

\author{
C. D. West
}

Date Published: September 2000

Prepared by

OAK RIDGE NATIONAL LABORATORY

Oak Ridge, Tennessee 37831-6285

managed by

UT-BATTELLE, LLC

for the

U.S. DEPARTMENT OF ENERGY

under contract DE-AC05-00OR22725 


\section{CONTENTS}

\section{Page}

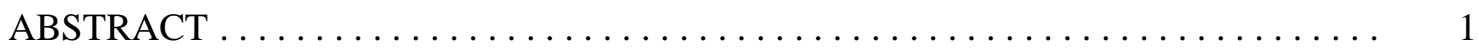

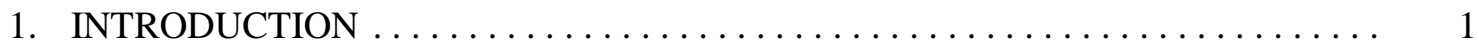

2. THE NUCLEATION PROCESS $\ldots \ldots \ldots \ldots \ldots \ldots \ldots \ldots \ldots \ldots \ldots \ldots \ldots \ldots \ldots \ldots \ldots \ldots$

3. THRESHOLD FOR MACROSCOPIC BUBBLE FORMATION $\ldots \ldots \ldots \ldots \ldots \ldots$

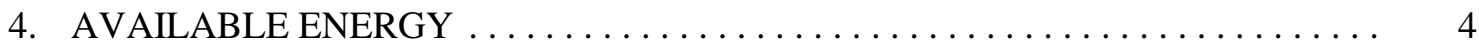

5. CALCULATION OF THRESHOLDS $\ldots \ldots \ldots \ldots \ldots \ldots \ldots \ldots \ldots \ldots \ldots \ldots \ldots \ldots$

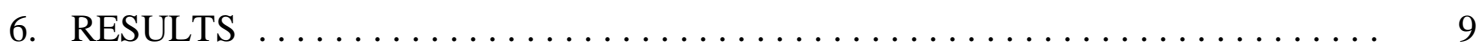

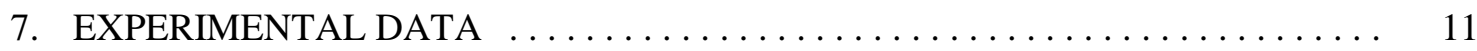

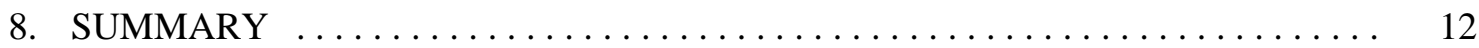

Appendix A: $\quad$ DOMINANCE OF KINETIC TERMS $\ldots \ldots \ldots \ldots \ldots \ldots \ldots \ldots \ldots \ldots$

Appendix B: PROPERTIES OF MERCURY FOR SNS TARGET

CAVITATION CALCULATIONS ................... 15

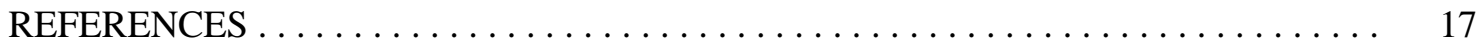




\section{LIST OF FIGURES}

$\begin{array}{lll}\text { Figure } & \text { Page }\end{array}$

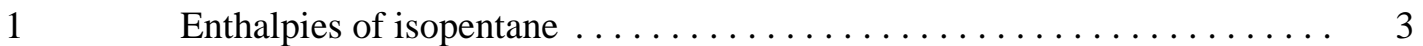

2 Range of ${ }^{202} \mathrm{Hg}$ in natural mercury ( second-order

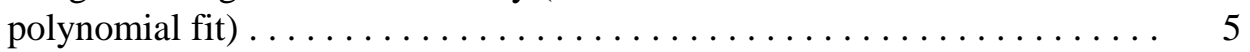

3 Bubble nucleation threshold for initial energies up to $20 \mathrm{MeV} \ldots \ldots \ldots \quad 10$

4 Bubble nucleation threshold for initial energies below $1 \mathrm{MeV} \ldots \ldots \ldots \quad 10$ 


\section{LIST OF TABLES}

$\begin{array}{lll}\text { Table } & \text { Page }\end{array}$

$1 \quad$ Some bubble formation experiments with isopentane $\ldots \ldots \ldots \ldots \ldots$

$2 \quad$ Range and $d E / d x$ for ${ }^{202} \mathrm{Hg}$ in natural mercury $\ldots \ldots \ldots \ldots \ldots \ldots$

3 Values of $R_{\mathrm{o}}$ calculated from the quintic equation and from

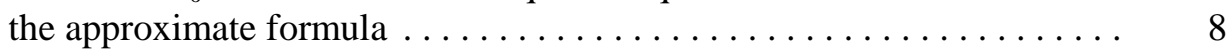

$4 \quad$ Radius of nucleation center, $R_{\mathrm{o}} \ldots \ldots \ldots \ldots \ldots \ldots \ldots \ldots \ldots \ldots \ldots \ldots$

$5 \quad$ Recoil energies and calculated threshold $\ldots \ldots \ldots \ldots \ldots \ldots \ldots \ldots$ 


\title{
CAVITATION IN A MERCURY TARGET
}

\author{
C. D. West
}

\begin{abstract}
Recent theoretical work on the formation of bubble nucleation centers by energetic particles leads to some reasonably credible calculations of the maximum negative pressure that might be sustained without bubble formation in the mercury target of the Spallation Neutron Source.
\end{abstract}

\section{INTRODUCTION}

In a sufficiently superheated liquid, the energy deposited by an energetic particle can cause local boiling that, after a short time, leads to a bubble of visible size. This effect was sought and observed in 1952 by Donald Glaser, during the course of his well-thought-out and persistent search for a new device that could reveal the tracks of high-energy particles. For a wonderful description of the desired properties of the detector and the thought process and experiments that led him to developing the bubble chamber and subsequently receiving a Nobel Prize for his research, see Glaser (1994).

The idea of bubble nucleation by the local formation of vapor evolved gradually; initially, the mechanism was imagined to be an electrostatic one, like the formation of droplets in the Wilson Cloud Chamber (which was already well known). In 1957, an influential paper written by Frederick Seitz - the first paper in the first edition of the first volume of a new journal, Physics of Fluids - quantified the local boiling theory, equating the energy expected to be deposited by the particle to the latent heat of vaporization and other smaller energy terms involved in the formation of the bubble (Seitz, 1957). This theory was beautifully confirmed by experimental measurements carried out by graduate student Georg Riepe (Riepe and Hahn, 1961). The experiments involved measuring the degree of superheating necessary to form bubbles around the tracks of ${ }^{210} \mathrm{Po},{ }^{212} \mathrm{Po}$, and ${ }^{212} \mathrm{Bi}$ alpha recoils in propane and Freon 12 . The liquid temperature was in the typical operating region of a bubble chamber-approximately two-thirds of the way between the normal boiling point and the critical temperature-and the liquid was initially held at its saturation pressure, so no boiling occurred. The pressure reduction needed to form bubbles from the alpha decay of polonium, or thorium $\mathrm{C}$ and thorium $\mathrm{C}^{\prime}$, dissolved in the liquid was then measured. The calculated energy balance of bubble nucleation and the energy available from the decay matched the prediction of Seitz's theory within a few percent, a great achievement.

When similar experiments were later carried out with cold liquids, below their normal boiling points, the liquids had to be placed under negative pressure (i.e., tensile stress) for macroscopic bubbles to be formed by alpha decay recoil particles (Hahn, 1961). The calculated energy balance typically differed by an order of magnitude from calculations based on Seitz's theory of the positive-pressure bubble chamber (Hahn and Peacock, 1963). It was soon recognized (West, 1967) that Seitz's basic physical model of local heating could also be applied to this situation, but that a different algebraic formulation of the model was appropriate for liquids under large negative pressures. However, although a fundamental reason for the discrepancy was thus identified, quantitative agreement between the calculated and measured pressure threshold 
for bubble formation, although improved, was still very poor compared with the agreement achieved by Riepe and Hahn's bubble chamber results.

More recently, a further development of the theory has led to much improved agreement (West, 1998), and that new model is applied in this report to calculate the minimum negative pressure that might be required to nucleate bubbles by recoiling mercury nuclei or heavy decay products of mercury in the target of the Spallation Neutron Source (SNS), planned at Oak Ridge.

\section{THE NUCLEATION PROCESS}

An energetic particle that is slowing down gives up its kinetic energy to atoms of the medium; that is, it heats the medium locally along its track. The heating can cause local vaporization, thus forming a small bubble. If that bubble is large enough, the pressure of vapor inside can overcome the surface tension forces tending to collapse it, and the bubble will grow indefinitely. A smaller bubble will soon collapse and disappear as surface tension raises the internal pressure enough to recondense the vapor. The growth, if it is to occur at all, must take place in a very short time, because the small amount of heat involved within a very small volume is soon dissipated, by conduction, into the surrounding liquid.

Two energetic conditions must be satisfied to turn a small heated volume of liquid into vapor: (1) there must be enough energy to provide the enthalpy of evaporation (this is the largest energy term in Seitz's bubble chamber theory), and (2) the liquid must be hot enough that the probability of spontaneous nucleation of boiling within that volume is high.

The second condition may require some further explanation. It has long been known that although most pure liquids have a well-defined boiling point, a clean sample in a clean container can often be raised to a much higher temperature before boiling erupts; in fact, the classic advice given to physicists (e.g., Chute, 1896) is to measure boiling points by placing a thermometer in the vapor above the boiling liquid rather than in the liquid itself. A simple criterion for spontaneous nucleation to occur, used by West (1998), is that the small heated volume be raised to the critical point, in which case it can certainly no longer remain liquid.

It turns out that in hot liquids, such as in a bubble chamber, the enthalpy difference, $H_{\mathrm{ca}}$, between the subcooled ambient condition and the critical point is less than the enthalpy of evaporation, $H_{\text {vap }}$, so that if the energy deposition from a particle is sufficient to evaporate enough liquid to form a bubble of the critical size (Seitz's criterion), it is also enough to ensure homogeneous nucleation. In a cold liquid, the opposite is true, and in order for a particle to have a high probability of forming a macroscopic bubble, it must deposit more energy than the Seitz criterion alone would require. Remember that Seitz explicitly and appropriately applied his theory to the former situation only. Figure 1 compares the two enthalpy terms for a particular liquid, isopentane, that has been used both in bubble chambers and in cavitation experiments (Table 1). It is unfortunate that no measurements have been reported on the temperature dependence of the threshold for negative- and positive-pressure bubble nucleation by the same source of particles, such as neutrons or a dissolved alpha emitter, in the same liquid —an experiment that begs to be done. 
Table 1. Some bubble formation experiments with isopentane

\begin{tabular}{llcl}
\hline \multicolumn{1}{c}{ Experiment or property } & \multicolumn{1}{c}{ Radiation } & $\begin{array}{c}\text { Temperature } \\
\left({ }^{\circ} \mathrm{C}\right)\end{array}$ & \multicolumn{1}{c}{ References } \\
\hline $\begin{array}{l}\text { Spinner experiment } \\
\text { Ultrasonic cavitation }\end{array}$ & ${ }^{210}$ Po decay & 20 & Hahn, 1961 \\
Ultrasonic cavitation & Fast neutrons & $\sim 21 ?$ & Lieberman, 1959 \\
$\begin{array}{l}\text { Normal boiling point } \\
\text { Negative-pressure bubble } \\
\text { chamber }\end{array}$ & Minimum ionization & $\sim 25$ & Hughes, 1960 \\
$\begin{array}{l}\text { Superheat limit at } \\
\text { atmospheric pressure }\end{array}$ & Cosmic? & 28 & Yaws, 1996 \\
$\begin{array}{l}\text { Normal bubble chamber } \\
\text { Critical temperature }\end{array}$ & Minimum ionization & 120 & Pless and Plano, 1956 \\
& & 159 & Blander and Katz, 1975 \\
& & 187 & Yaws, 1996 \\
\hline
\end{tabular}

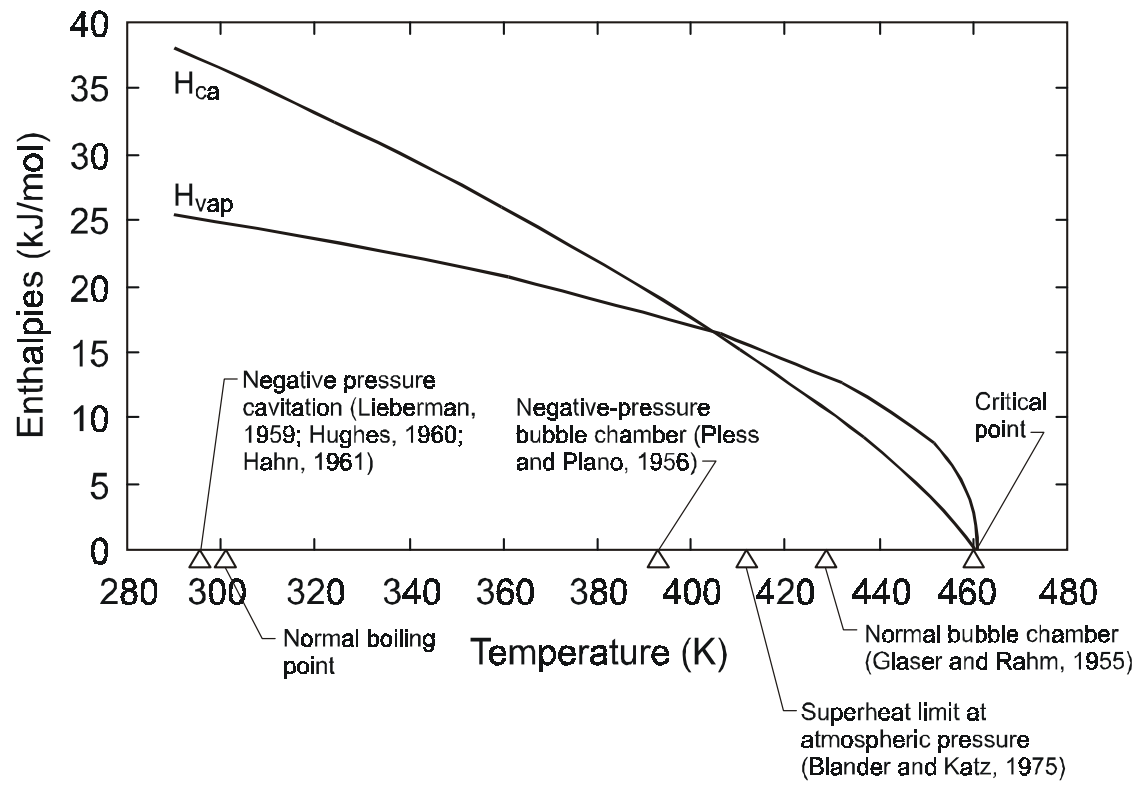

Fig. 1. Enthalpies of isopentane. 


\section{THRESHOLD FOR MACROSCOPIC BUBBLE FORMATION}

Estimation of the minimum negative pressure that will form a macroscopic cavitation bubble from a certain amount of energy, $E_{\text {av }}$, provided by an energetic particle is rather complicated, even in the particular case where the linear rate of energy deposition, $d E / d x$, is independent of the energy (West, 1998). Besides the enthalpy difference, $H_{\text {ca }}$, the threshold depends on the surface tension and density of the liquid, its density and pressure at the critical point, its viscosity, its thermal diffusivity, and the value of $d E / d x$ or the initial energy of the particle.

Fortunately, the problem is greatly simplified if the energy requirements of the initial bubble formation are dominated by kinetic terms, that is, by the viscosity and/or the amount of kinetic energy that must be imparted to the liquid around the growing bubble if it is to reach the critical size before its heat content is lost by conduction. It turns out that this is true for mercury, as shown in Appendix A. In such a case, the minimum negative pressure $P_{\text {neg }}$ (threshold) that will lead to a bubble of macroscopic size is given by a simple equation, Eq. (63) in West (1998):

$$
P_{\text {neg }}(\text { threshold })=2 \sigma \sqrt[3]{\frac{4 \pi \rho_{\mathrm{crit}} H_{\mathrm{ca}}}{3 E_{\mathrm{av}}}}
$$

where

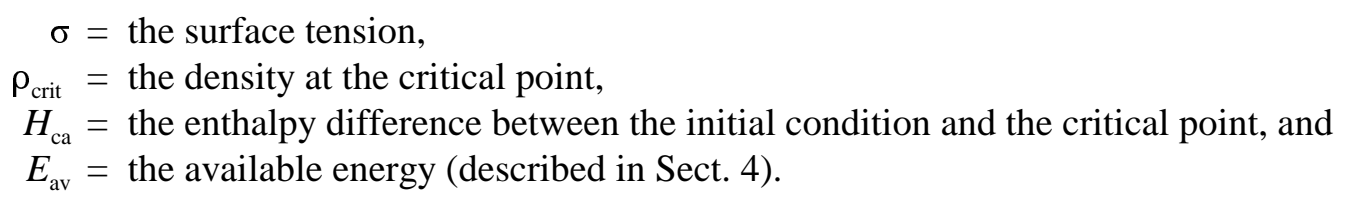

Liquid enthalpy values do not appear to be available for negative-pressure conditions, but liquid enthalpy is not very dependent on pressure and for convenience is here evaluated at the initial temperature of the liquid and at a pressure $1 \%$ above the corresponding saturation pressure (to ensure that the evaluation is made under conditions where the substance is a liquid, not a vapor). The mercury properties needed for the calculations were taken from the Yaws data base (Yaws, 1996) and are listed in Appendix B.

\section{AVAILABLE ENERGY}

Peter Fu kindly provided calculated values for the range and $d E / d x$ of ${ }^{202} \mathrm{Hg}$ in a medium of natural mercury (Fu, 1999). Some of his data, calculated from a version of the SPAR code that he modified to work with higher-atomic-number particles, are listed in Table 2. The upper energy limit shown in the table is approximately $20 \mathrm{MeV}$, which would be the maximum energy that could be given to an elastically recoiling mercury atom by a $1-\mathrm{GeV}$ proton-the proton energy in the SNS.

Examination of Table 2 shows that in this range of energies, the linear rate of energy deposition, $d E / d x$, is highest at the beginning of the particle's track. Therefore, the energy available, $E_{\mathrm{a}}$, over any distance less than the range is greatest at the beginning of the track.

Because $d E / d x$ is energy dependent, the range is not proportional to the initial energy, but Fig. 2 (prepared with TK Solver) shows that a second-order polynomial relationship fits the data well. 
Table 2. Range and $d E / d x$ for ${ }^{202} \mathrm{Hg}$ in natural mercury

\begin{tabular}{ccc}
\hline $\begin{array}{c}\text { Initial energy } \\
(\mathrm{MeV})\end{array}$ & $\begin{array}{c}\text { Range } \\
\left(\times 10^{-5} \mathrm{~cm}\right)\end{array}$ & $\begin{array}{c}\text { Initial } d E / d x \\
\left(\times 10^{5} \mathrm{MeV} / \mathrm{cm}\right)\end{array}$ \\
\hline 21.15 & 17.711 & 1.461 \\
19.41 & 16.498 & 1.423 \\
17.81 & 15.369 & 1.388 \\
14.99 & 13.289 & 1.325 \\
10.63 & 9.873 & 1.226 \\
5.34 & 5.346 & 1.111 \\
4.90 & 4.949 & 1.104 \\
2.07 & 2.311 & 1.034 \\
1.04 & 1.290 & 0.978 \\
0.956 & 1.202 & 0.970 \\
0.738 & 0.974 & 0.944 \\
0.523 & 0.743 & 0.904 \\
0.480 & 0.694 & 0.894 \\
0.203 & 0.365 & 0.772 \\
0.102 & 0.225 & 0.663 \\
0.051 & 0.142 & 0.552 \\
\hline
\end{tabular}

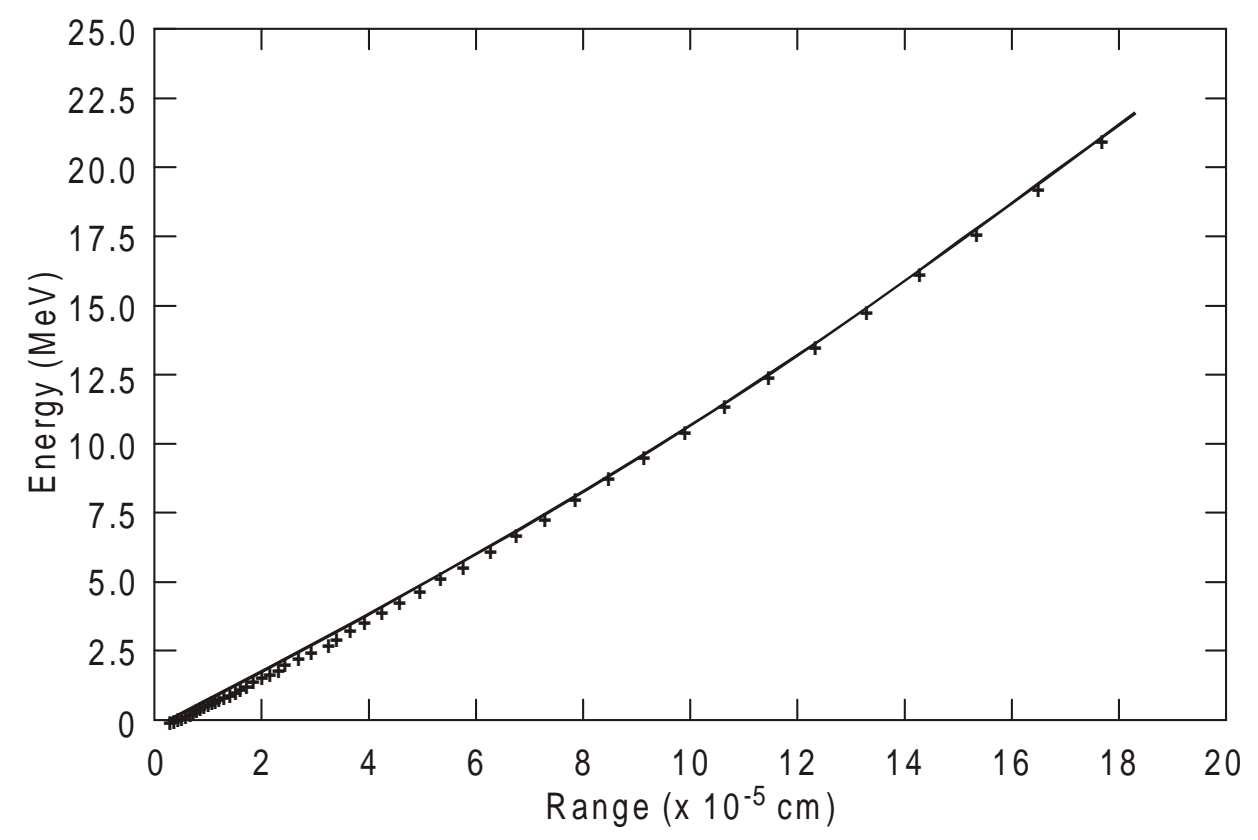

Fig. 2. Range of ${ }^{202} \mathrm{Hg}$ in natural mercury ( second-order polynomial fit). 
Changing to S.I. units for convenience in the calculations to follow, the equation of the fitted curve, with range $R$ measured metres and energy in joules, is

$$
R(E) \approx r_{1}+r_{2} E+r_{3} E^{2}
$$

where

$$
\begin{aligned}
& r_{1}=2.091 \times 10^{-8} \mathrm{~m}, \\
& r_{2}=6.275 \times 10^{5} \mathrm{~m} / \mathrm{J}, \text { and } \\
& r_{3}=-3.371 \times 10^{16} \mathrm{~m} / \mathrm{J}^{2} .
\end{aligned}
$$

The enthalpy that must be added to form a sphere of fluid with radius $R_{\mathrm{o}}$ at the critical point is

$$
E=\frac{4}{3} \pi R_{\mathrm{o}}^{3} \rho_{\mathrm{crit}} H_{\mathrm{ca}},
$$

and the largest possible nucleation center is formed when

$$
\frac{4}{3} \pi R_{\mathrm{o}}^{3} \rho_{\text {crit }} H_{\mathrm{ca}}=E_{\mathrm{av}}
$$

where $E_{\mathrm{av}}$ is the energy deposited, by the recoil, in a distance of $2 R_{\mathrm{o}}$ [see Sect. 8.3 of West (1998)].

If the recoil track is very long, the largest nucleation center will be formed in the first part of the track where $d E / d x$ is highest; if the track is short enough, it will be formed using the whole recoil energy.

In the former case, one can calculate the energy $E_{\mathrm{av}}$ deposited in a distance $2 R_{\mathrm{o}}$ from the beginning of the track by writing

$$
\text { Range }\left(E_{\text {initial }}\right)-\text { Range }\left(E_{\text {initial }}-E_{\text {av }}\right)=2 R_{\mathrm{o}} \text {. }
$$

Now substitute the range-vs-energy relationship of Eq. (2),

$$
\left(r_{1}+r_{2} E_{\text {initial }}+r_{3} E_{\text {initial }}^{2}\right)-\left[r_{1}+r_{2}\left(E_{\text {initial }}-E_{\text {av }}\right)+r_{3}\left(E_{\text {initial }}-E_{\text {av }}\right)^{2}\right]=R_{\mathrm{o}},
$$

or, rearranging and simplifying,

$$
E_{\mathrm{av}}^{2}-\left(2 E_{\text {initial }}+r_{2} / r_{3}\right) E_{\mathrm{av}}+2 R_{\mathrm{o}} / r_{3}=0
$$

Now simplify the appearance of Eq. (3) by writing

$$
H=\frac{4}{3} \pi \rho_{\text {crit }} H_{\mathrm{ca}} \text {. }
$$


The variable $H$ is actually the enthalpy per unit volume needed to raise the liquid to the critical point multiplied by the constant $4 \pi / 3$. Equation (3) now reads

$$
E_{\mathrm{av}}=H R_{\mathrm{o}}{ }^{3},
$$

and substituting that relationship into Eq. (4) yields

$$
H^{2} R_{\mathrm{o}}^{6}-\left(2 E_{\text {initial }}+r_{2} / r_{3}\right) H R_{\mathrm{o}}^{3}+2 R_{\mathrm{o}} / r_{3}=0
$$

or dividing by $H^{2} R_{0}$,

$$
R_{\mathrm{o}}{ }^{5}-\frac{2 E_{\text {initial }}+r_{2} / r_{3}}{H} R_{\mathrm{o}}^{2}+\frac{2 / r_{3}}{H^{2}}=0 .
$$

The roots of this quintic equation can easily be found numerically, for example by using the BISECT program in the TK Solver library. However, in the range of values for $E_{\text {initial }}$ of interest in this report $\left(E_{\text {initial }}<20 \mathrm{MeV}\right)$, it turns out that the fifth-order term is negligible.

For example, if $E_{\text {initial }}=20 \mathrm{MeV}$,

$$
\begin{gathered}
E_{\text {initial }}=20 \mathrm{MeV}=3.204 \times 10^{-12} \mathrm{~J}, \\
r_{2} / r_{3}=6.275 \times 10^{5} /\left(-3.371 \times 10^{16}\right)=-18.61 \times 10^{-12} \mathrm{~J}, \\
H=(4 \pi / 3) \times 17.746 \times 10^{3} \times 62.00 \times 10^{3}=4.608 \times 10^{9} \mathrm{~J} / \mathrm{m}^{3},
\end{gathered}
$$

and Eq. (6a) becomes

$$
R_{\mathrm{o}}^{5}+2.65 \times 10^{-21} R_{\mathrm{o}}^{2}-2.79 \times 10^{-36}=0
$$

The solution for $R_{\mathrm{o}}$ obtained by ignoring the fifth-order term is

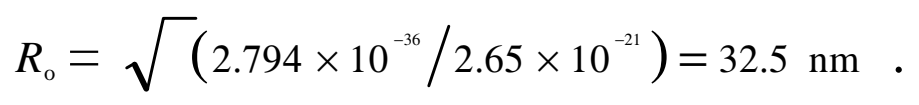

Then $R_{\mathrm{o}}{ }^{5} \sim 3.6 \times 10^{-38}$, which is two orders of magnitude less than the constant term of $2.79 \times 10^{-36}$. Therefore Eq. $(6 a)$, for this liquid in this range of particle energies, can be approximated by

$$
R_{\mathrm{o}} \approx \sqrt{\frac{1}{H\left(r_{3} E_{\text {initial }}+r_{2} / 2\right)}} .
$$

To verify this, Table 3 compares values of $R_{\mathrm{o}}$ computed from Eqs. $(6 a)$ and $(6 b)$ over a range of initial energies from 0.1 to $20 \mathrm{MeV}$. The values from Eq. $(6 b)$ are all within $1 \%$ of the 
Table 3. Values of $R_{0}$ calculated from the quintic equation and from the approximate formula

\begin{tabular}{ccc}
\hline $\begin{array}{c}\text { Initial energy } \\
(\mathrm{MeV})\end{array}$ & $\begin{array}{c}R_{\mathrm{o}} \text { from Eq. } \\
(\mathrm{nm})\end{array}$ & $\begin{array}{c}R_{\mathrm{o}} \text { from Eq. } \\
(\mathrm{nm})\end{array}$ \\
\hline 0.1 & 26.264 & 26.322 \\
0.2 & 26.286 & 26.345 \\
0.4 & 26.331 & 26.391 \\
0.8 & 26.422 & 26.483 \\
1.0 & 26.467 & 26.529 \\
2.0 & 26.700 & 26.765 \\
4.0 & 27.182 & 27.255 \\
8.0 & 28.231 & 28.322 \\
10.0 & 28.802 & 28.905 \\
20.0 & 32.274 & 32.478 \\
\hline
\end{tabular}

solution from Eq. (6a), and the rest of these calculations will therefore use the approximate, but much simpler, Eq. $(6 b)$.

The largest nucleation center that could possibly be formed, if all of the initial recoil energy were used, would have a radius $R_{\mathrm{o}}$ such that [see Eq. (3)]

$$
E_{\text {initial }}=\frac{4}{3} \pi R_{\mathrm{o}}^{3} \rho_{\text {crit }} H_{\mathrm{ca}}
$$

Substituting $H=(4 \pi / 3) \rho_{\text {crit }} H_{\text {ca }}$ and rearranging yields

$$
R_{\mathrm{o}}=\sqrt[3]{\frac{E_{\text {initial }}}{H}}
$$

However, if the total range of a recoil with energy $E_{\text {initial }}$ is greater than $2 R_{0}$, only that part of the energy deposited within a distance $2 R_{\mathrm{o}}$ would be available to the nucleation center, and Eq. (7) would apply. A convenient way of expressing this, particularly if TK Solver is used to evaluate the equations, based on the approximate Eq. (6b), is

$$
R_{\mathrm{o}}=\operatorname{MIN}\left[\sqrt[3]{\frac{E_{\text {initial }}}{H}}, \sqrt{\frac{1}{H\left(r_{3} E_{\text {initial }}+r_{2} / 2\right)}}\right],
$$

where, in the language of TK Solver, $\operatorname{MIN}(X, Y)$ means the smaller of the two values $X$ and $Y$.

Table 4 shows the two parenthetical components in Eq. (8) and the corresponding calculated value of $R_{0}$. 
Table 4. Radius of nucleation center, $R_{0}{ }^{a}$

\begin{tabular}{cccc}
\hline & & \multicolumn{2}{c}{$\begin{array}{c}R_{\mathrm{o}} \\
(\mathrm{nm})\end{array}$} \\
\cline { 2 - 4 }$E_{\text {initial }}$ & $\begin{array}{c}\text { Based on Eq. (7) } \\
\text { (using all the recoil } \\
\text { energy) }\end{array}$ & Based on Eq. $(6 b)$ & Based on Eq. (8) \\
\hline 0.1 & $\mathbf{1 5 . 1 5 0}$ & 26.322 & \\
0.2 & $\mathbf{1 9 . 0 8 7}$ & 26.345 & $\mathbf{1 5 . 1 5 0}$ \\
0.4 & $\mathbf{2 4 . 0 4 8}$ & 26.391 & $\mathbf{1 9 . 0 8 7}$ \\
0.8 & 30.299 & $\mathbf{2 6 . 4 8 3}$ & $\mathbf{2 4 . 0 4 8}$ \\
1.0 & 32.639 & $\mathbf{2 6 . 5 2 9}$ & $\mathbf{2 6 . 4 8 3}$ \\
2.0 & 41.122 & $\mathbf{2 6 . 7 6 5}$ & $\mathbf{2 6 . 5 2 9}$ \\
4.0 & 51.811 & $\mathbf{2 7 . 2 5 5}$ & $\mathbf{2 7 . 2 5 5}$ \\
8.0 & 65.278 & $\mathbf{2 8 . 3 2 2}$ & $\mathbf{2 8 . 3 2 2}$ \\
10.0 & 70.318 & $\mathbf{2 8 . 9 0 5}$ & $\mathbf{2 8 . 9 0 5}$ \\
20.0 & 88.595 & $\mathbf{3 2 . 4 7 8}$ & $\mathbf{3 2 . 4 7 8}$ \\
\hline
\end{tabular}

${ }^{a}$ Note that for energies above about $0.5 \mathrm{MeV}$, the recoil track is longer than the nucleation center diameter, so only a fraction of the recoil energy is available to initiate a single bubble.

\section{CALCULATION OF THRESHOLDS}

Now that $R_{\mathrm{o}}$ has been calculated, $E_{\mathrm{av}}$ can be determined from the relationship $E_{\mathrm{av}}=H R_{\mathrm{o}}{ }^{3}$, and then the minimum negative pressure for bubble formation can be obtained from Eq. (1). However, there is a more direct method.

If we substitute $E_{\mathrm{av}}=H R_{\mathrm{o}}{ }^{3}$, from Eq. (5), directly into Eq. (1), remembering that $H=(4 \pi / 3) \rho_{\text {crit }} H_{\text {ca }}$, the result is

$$
P_{\text {neg }}(\text { threshold })=\frac{2 \sigma}{R_{\mathrm{o}}} .
$$

Such simplicity may seem surprising, but it is a consequence of the basic nucleation mechanism: a bubble of radius $r$ feels an inward force from surface tension that tends to collapse it. That force is equivalent to an inward pressure of $2 \sigma / r$, and any outward pressure (either from vapor inside the bubble or from an external negative pressure) that is greater than $2 \sigma / r$ will cause the bubble to grow, hence Eq. (9).

To calculate the thresholds, for mercury recoils with initial energies in the range $0.1-20 \mathrm{MeV}$, use Eq. (8) to evaluate $R_{\mathrm{o}}$, and substitute that value in Eq. (9) to calculate the threshold.

\section{RESULTS}

Figures 3 and 4 show the negative-pressure threshold calculated as a function of the initial energy of the recoil. The sudden change in the slope, at an initial energy of $\sim 0.5 \mathrm{MeV}$, represents 


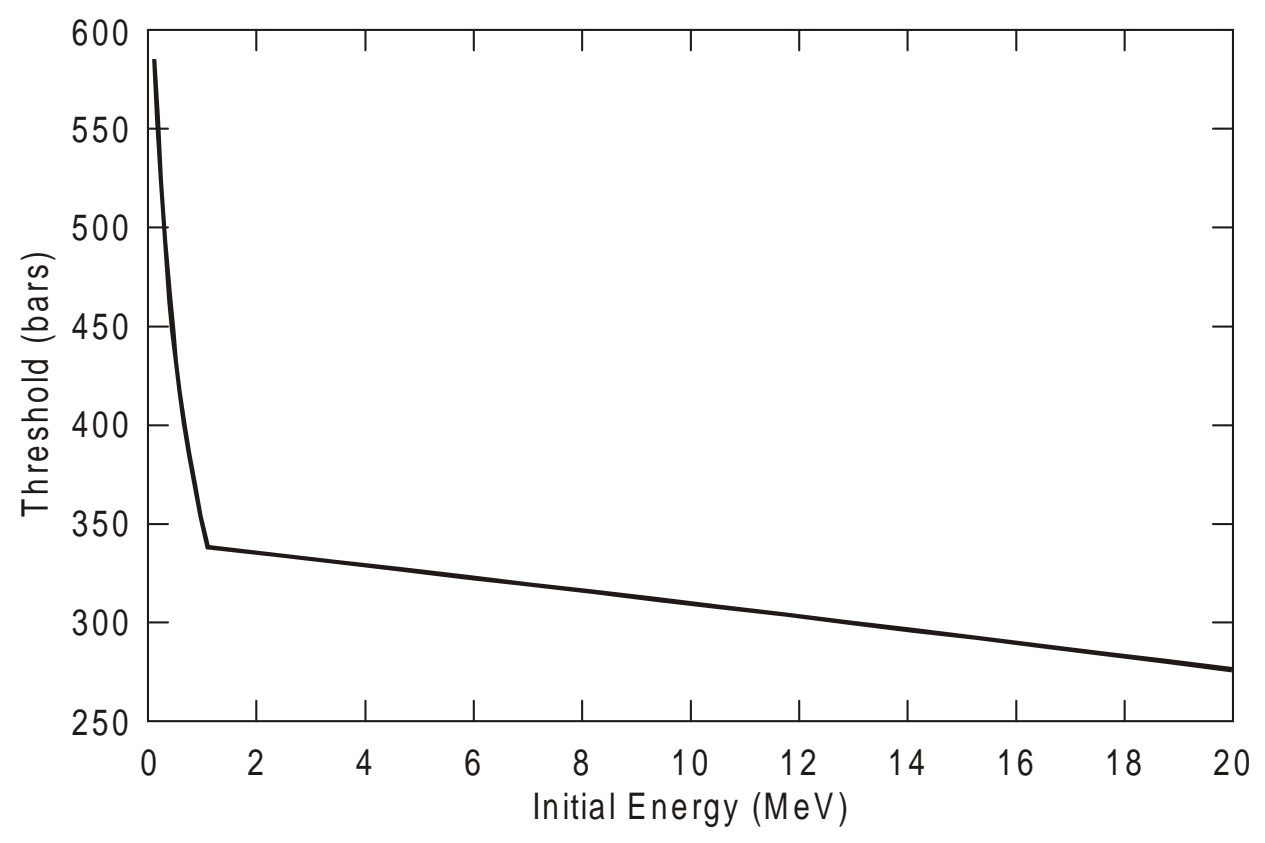

Fig. 3. Bubble nucleation threshold for initial energies up to $20 \mathrm{MeV}$.

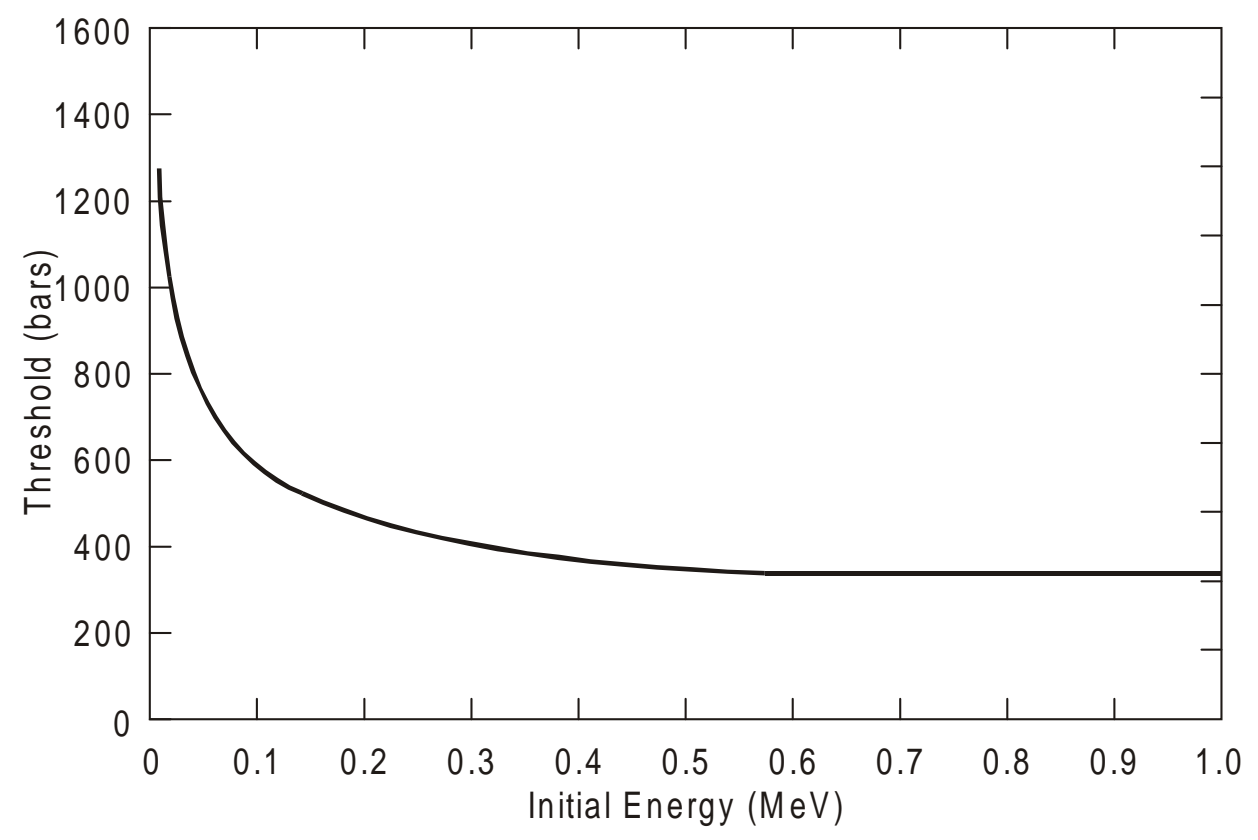

Fig. 4. Bubble nucleation threshold for initial energies below $1 \mathrm{MeV}$. 
the point above which the range of the particle is so long that not all of its initial energy is deposited in a region small enough to form a single nucleation center. At higher energies, the threshold falls only slowly, as $d E / d x$ gradually gets larger. In the range $0.5-20 \mathrm{MeV}$, the negative-pressure threshold is in the range $307 \pm 30$ bars. Below $0.5 \mathrm{MeV}$, it rises rapidly to over 700 bars at $50 \mathrm{keV}$.

I know of no published data concerning the radioactive or recoil particles expected to be found in the mercury target of the SNS. However, one can speculate on the outcome of various physical processes. As stated earlier, the maximum energy a mercury atom can receive from an incoming proton is $20 \mathrm{MeV}$, but the negative-pressure waves that might give rise to cavitation are generated by the reflection of positive-pressure waves created when the proton beam strikes and heats the target. Therefore, the mercury recoils will see no negative pressure to nucleate bubbles unless pressure waves continue to reverberate with a high amplitude until the next proton pulse, $15 \mathrm{~ms}$ later. This would require a high amplitude to be maintained following 200 or more reflections. The SNS Project is planning experiments to observe the reverberations, but such a long period of almost undiminished echoes seems unlikely.

Another possible source of recoils would be neutrons, or other particles, emitted by activated materials in the target mercury or its container. It would probably be conservative to assume that the maximum energy of such a particle would be $10 \mathrm{MeV}$, in which case the maximum energy it could give to a mercury nucleus, in a head-on elastic collision, would be $\sim 200 \mathrm{keV}$. Or if the mercury itself were transmuted, without a great change of mass in the transmutation, the resulting isotope might recoil upon decay through alpha emission. If an alpha particle were emitted with an energy of, say, $5 \mathrm{MeV}$, then the maximum recoil energy of a particle of mass $\sim 200$ amu would be $\sim 400 \mathrm{keV}$. The calculated negative-pressure thresholds for such events are shown in Table 5.

Table 5. Recoil energies and calculated threshold

\begin{tabular}{cc}
\hline $\begin{array}{c}\text { Mercury recoil energy } \\
(\mathrm{MeV})\end{array}$ & $\begin{array}{c}\text { Calculated threshold } \\
\text { (bars) }\end{array}$ \\
\hline 2.0 & 270 \\
0.4 & 370 \\
0.2 & 470 \\
\hline
\end{tabular}

\section{EXPERIMENTAL DATA}

Briggs (1953) measured the cavitation threshold of mercury in Pyrex glass using his spinner method. Even taking extreme measures to clean the glass tube and to purify and degas the mercury, the maximum negative pressure sustained was 425 bars at $27^{\circ} \mathrm{C}$ (much lower than the $150^{\circ} \mathrm{C}$ expected in the SNS target), and in other circumstances the threshold was more typically less than 50 bars. Experiments by Taleyarkhan et al. (1998) and Moraga (1999) with mercury that had not been thoroughly degassed led to cavitation at less than 1 bar of negative pressure.

For comparison, calculations by Taleyarkhan and Kim (1998) of the negative-pressure pulse following reflection of the initial positive-pressure wave give a value of more than 200 bars in the bulk mercury and more than 600 bars near the target walls (if there was no significant cavitation). Experiments are planned to measure the amplitude of successive reflections. However, the experimental data mentioned in the previous paragraph seem to indicate that in a 
practical mercury target, other mechanisms are likely to lead to a negative-pressure threshold for cavitation that is smaller (more easily reached) than the theoretical limit imposed by radiationinduced nucleation.

\section{SUMMARY}

One can make simple calculations of the ultimate negative pressure likely to be sustainable by the mercury of the SNS target. Radiation is likely to set an upper limit of $\sim 400$ bars, although dissolved or entrained gas will likely prevent such high tensile stresses from being reached in a practical target assembly. 


\section{Appendix A:}

\section{DOMINANCE OF KINETIC TERMS}

Section 7.3 of West (1998) describes how to determine whether Eq. (1) of the present report is appropriate. In liquids where the dynamic terms (viscous losses and the kinetic energy given to the liquid around the rapidly growing bubble) are dominant, the bubble cannot grow fast enough to preserve the initial energy deposited by the nucleating particle. Instead, that energy is lost almost immediately by conduction so that the internal energy, and therefore pressure, inside the bubble soon becomes very small. To continue bubble growth beyond this stage, the negative pressure alone must be able to overcome the inward forces of surface tension, that is,

$$
P_{\text {neg }}(\text { threshold }) \geq \frac{2 \sigma}{R_{\text {o }}},
$$

where $\sigma$ is the surface tension and $R_{\mathrm{o}}$ the initial radius of the nucleation center. As indicated in Eq. (3) of this report,

$$
R_{\mathrm{o}}=\sqrt[3]{\frac{3 E_{\mathrm{av}}}{4 \pi \rho_{\text {crit }} H_{\mathrm{ca}}}} .
$$

The section referred to above (West, 1998) shows that the distinction between high and low dynamic-loss cases is determined by comparing the results predicted by Eqs. (44) and (50) of that report. With a slight change of nomenclature (substituting $E_{\text {av }}$ for $E_{\text {recoil }}$ ), Eq. (50) is identical to Eq. (A.2) above.

Using the TK Solver routines developed for the work reported by West (1998), the results for mercury are calculated as follows:

\begin{tabular}{crc} 
& \multicolumn{2}{c}{$P_{\text {neg }}$ (threshold) } \\
$E_{\text {av }}$ & \multicolumn{2}{c}{ (bars) } \\
\cline { 2 - 3 }$(\mathrm{MeV})$ & Eq. (44) & Eq. (50) \\
\hline 20 & 299 & $101^{*}$ \\
2 & 22,976 & $218^{*}$ \\
0.2 & $2,230,447$ & 470
\end{tabular}

In all cases Eq. (50) is by far the lower value, indicating that Eq. (50) or (A.2) is the appropriate one to use.

*These values are lower than those that appear in Table 5, which is seemingly similar. The energy listed in Table 5 is the total recoil energy, not all of which is available for bubble formation. 
Appendix B:

PROPERTIES OF MERCURY FOR SNS TARGET

CAVITATION CALCULATIONS

\begin{tabular}{|c|c|c|c|}
\hline Property & Units & Value & Notes \\
\hline $\mathrm{Zp}$ & & 80 & Charge number of recoiling particle \\
\hline$T_{\mathrm{amb}}$ & $\mathrm{K}$ & 423.15 & Initial temperature \\
\hline \multicolumn{4}{|c|}{ Data obtained from Yaws database } \\
\hline Mwt & $\mathrm{g} / \mathrm{mol}$ & 200.59 & Molecular weight \\
\hline $\mathrm{Z}_{\ell}$ & & 80 & Charge number of medium \\
\hline $\mathrm{rho}_{\ell}$ & $\mathrm{kg} / \mathrm{m}^{3}$ & 13,270 & Density of liquid \\
\hline sigma & $\mathrm{mN} / \mathrm{m}$ & 447.47 & Surface tension \\
\hline Cpliq & $\mathrm{J} / \mathrm{mol} \cdot \mathrm{K}$ & 27.54 & Specific heat \\
\hline eta & $\mathrm{mPa} / \mathrm{s}$ & 1.165 & Viscosity \\
\hline kliq & $\mathrm{w} / \mathrm{m} \cdot \mathrm{K}$ & 10.05 & Thermal conductivity \\
\hline$P_{\text {crit }}$ & bars & 1608 & Critical pressure \\
\hline$T_{\text {crit }}$ & $\mathrm{K}$ & 1735 & Critical temperature \\
\hline rho $_{\text {crit }}$ & $\mathrm{kg} / \mathrm{m}^{3}$ & 3559.7 & Density at critical point \\
\hline$H_{\mathrm{ca}}$ & $\mathrm{Btu} / \mathrm{lb}$ & 132.95 & Enthalpy difference, ambient to critical \\
\hline \multicolumn{4}{|c|}{ Data calculated from Yaws data } \\
\hline $\mathrm{rho}_{\ell}$ & $\mathrm{kmol} / \mathrm{m}^{3}$ & 66.155 & Density of liquid \\
\hline rho $_{\text {crit }}$ & $\mathrm{kmol} / \mathrm{m}^{3}$ & 17.746 & Density at critical point \\
\hline$H_{\mathrm{ca}}$ & $\mathrm{kJ} / \mathrm{mol}$ & 61.99 & Enthalpy difference, ambient to critical \\
\hline$D$ & $\mathrm{~m}^{2} / \mathrm{s}$ & $5.516 \times 10^{-6}$ & Thermal diffusivity \\
\hline eta $_{\text {eff }}$ & $\mathrm{mPa} \cdot \mathrm{s}$ & 19.465 & $\begin{array}{l}\text { Effective viscosity, Eq. (34) in } \\
\text { West (1998) }\end{array}$ \\
\hline
\end{tabular}




\section{REFERENCES}

Blander, M. and Katz, J. L. 1975. "Bubble Nucleation in Liquids," AIChE Journal 21, 5, 833-848, September.

Briggs, L. J. 1953. "The Limiting Negative Pressure of Mercury in Pyrex Glass," Jnl. Appl. Phys. 24, 1, 488-490, April.

Chute 1896. "Physical Laboratory Manual," Section 67, D. C. Heath \& Co., 1896.

Fu, Chia Y. 1999. Private communication with author.

Glaser, D. A. 1994. "Invention of the Bubble Chamber and Subsequent Events," Nucl. Phys. B (Proc. Suppl.) 36, 3-18.

Glaser, D. A. and Rahm, D. C. 1955. "Characteristics of Bubble Chambers," Physical Review 97, $2,474-479$.

Hahn, B. 1961. "The Fracture of Liquids under Stress Due to Ionizing Particles," Nuovo Cimento 22, 650-653.

Hahn, B. and Peacock, R. N. 1963. "Ultrasonic Cavitation Induced by Neutrons," Nuovo Cimento 28, 2, 334-340, April 16.

Hughes, A. L. 1960. "An Exploration of the Possibility of Employing Ultrasonic Radiation to Sensitize a Bubble Chamber," in Proceedings of the International Conference on Instrumentation for High Energy Physics, II b.1, E. O. Lawrence Radiation Laboratory, Berkeley, California. September 12-14.

Lieberman, D. 1959. "Radiation Induced Cavitation," Phys. Fluids 2, 4, 466-468.

Moraga, F. and Taleyarkhan, R. P. 1999. "Static and Transient Cavitation Threshold Measurements for Mercury," in Proceedings of the 3rd International Topical Meeting on Accelerator Applications (AccApp '99), Long Beach, California, pp. 301-307, November.

Pless, I. A. and Plano, R. J. 1956. "Negative Pressure Isopentane Bubble Chamber," Rev. Sci. Instr. 27, 11, 935-937, November.

Riepe, G. and Hahn, B. 1961. "Untersuchungen zum Mechanismus der Blasenbildung in Freon-12 und Propan durch Rückstosskerne einiger $\alpha$-Strahler," Helv. Phys. Acta 34, 8, 865-892.

Seitz, F. 1957. "On the Theory of the Bubble Chamber," Phys. Fluids 1, 1, 2-13.

Taleyarkhan, R. P. and Kim, S. H. 1998. "Comparison of Predictions Against Thermal Shock Data in Mercury Targets," in Proceedings of the 2nd International Topical Meeting on Accelerator Applications (AccApp '98), Gatlinburg, Tennessee, September.

Taleyarkhan, R. P., Moraga, F., and West, C. D. 1998. "Experimental Determination of Cavitation Thresholds in Water and Mercury," in Proceedings of the 2nd International Topical Meeting on Accelerator Applications (AccApp '98), Gatlinburg, Tennessee, pp. 650-657, September.

West, C. D. 1967. Cavitation Nucleation by Energetic Particles, AERE-R5486, June.

West, C. D. 1998. Cavitation Bubble Nucleation by Energetic Particles, ORNL/TM-13683, December.

Yaws, C. L. 1996. "Floppy Disk Databases of Thermodynamic and Transport Properties," TREI, 685 Birchwood, Port Neches, Texas 77651. 


\section{INTERNAL DISTRIBUTION}

1. Chia Y. Fu

2. T. A. Gabriel

3. J. R. Haines

4. J. B. Roberto

5. R. P. Taleyarkhan
6-8. C. D. West

9. D. M. Williams

10-11. Central Research Library

12. ORNL Laboratory Records-RC

13-14. ORNL Laboratory Records-OSTI

\section{EXTERNAL DISTRIBUTION}

15. Prof. R. E. Apfel, Yale University, 9 Hillhouse Avenue, New Haven, CT 06520-8286

16. Dr. G. Bauer, Paul Scherrer Institute, CH5232, Villigen, Switzerland

17. Prof. F. d'Errico, Yale University School of Medicine, Department of Therapeutic Radiology, Division of Radiological Physics, 333 Cedar St., HRT-219, New Haven, CT 06510

18. Herr Dr. Georg Riepe, Im Schmidtenloch 59, D-53894 Mechernich, Germany

19. Dr. Carl L. Yaws, TREI, 685 Birchwood, Port Neches, TX 77651

20. D. K. Wilfert, U.S. Department of Energy, Bldg. 701SCA, MS-6477, P.O. Box 2001-LM-14, Oak Ridge, TN 37831-6477 